\title{
The Effects of Atorvastatin on the Migraine Pathophysiology in Nitroglycerin Induced Migraine in Ovariectomized Rats
}

\author{
Ahmet Can Hicyilmaz' ${ }^{1}$, Kadriye Akgun-Dar ${ }^{1}$ \\ 'Istanbul University, Faculty of Science, Department of Biology, Zoology, Istanbul, Turkey
}

ORCID IDs of the authors: A.C.H. 0000-0003-4649-4264; K.A.D. 0000-0003-2060-1199

Please cite this article as: Hicyilmaz AC, Akgun-Dar K, The Effects of Atorvastatin on the Migraine Pathophysiology in Nitroglycerin Induced Migraine in Ovariectomized Rats. Eur J Biol 2019;78(1): 11-22.

\begin{abstract}
Objective: Migraine is one of the common primary headaches which affects the majority of the population. However, in spite of increasing information on migraine pathophysiology and various researches, the underlying mechanisms of migraine attacks still not completely understood. Statins have antioxidant, anti-inflammatory neuroprotective effects and they might be a useful drug for curing neurodegenerative disorders. There are several studies suggesting nitric oxide (NO) causes migraine attacks in migraine pathogenesis. We aimed to investigate the effects of atorvastatin (AT) which is a member of the statin family, on migraine pathophysiology in ovariectomized female rats in which migraine was stimulated using nitroglycerine (NTG).

Materials and Methods: In the study, ovariectomized adult Sprague Dawley female rats were divided into 4 groups; control, NTG, AT, NTG+AT. We examined immunohistochemically inducible nitric oxide (iNOS), endothelial nitric oxide (eNOS), neuronal nitric oxide (nNOS), matrix metalloproteinase-2 (MMP-2), $\beta$-catenin expression on brain sections and biochemically c-fos, calcitonin gene-related peptide (CGRP), $\beta$-catenin, calcium-binding protein B (S100B), NO, total antioxidant capacity (TAS) and total oxidant capacity (TOS) levels.
\end{abstract}

Results: Our results showed that AT was immunohistochemically increasing eNOS and nNOS levels, and reducing iNOS. In brain homogenates AT was reducing S100B, CGRP, c-fos, total Nitrite-Nitrate, $\beta$-catenin but increasing TAS and TOS. There was no change in MMP-2. Also, our findings showed that AT could inhibit astroglial activity with its anti-inflammatory effect and showed a protective effect towards blood-brain barrier and reduced the risk of possible neurodegenerative diseases in rats with migraine.

Conclusion: Our findings showed that AT could inhibit astroglial activity with its anti-inflammatory effect and showed a protective effect towards blood-brain barrier and reduced the risk of possible neurodegenerative diseases in rats with migraine. Our results will provide a significant contribution to studies in this field.

Keywords: Migraine, nitroglycerin, atorvastatin, ovariectomized, rat

\section{INTRODUCTION}

Migraine, one of the common primary headaches which affect the majority of the population, is generally characterized with nausea, vomiting, sensitivity to sound and light, along with a unilateral and severe headache (1). Migraine is a brain disorder that affects $11 \%$ of the population and is common in women (2). Generally, the activation and sensitization of trigeminovascular pain path (which is believed to be associated with migraine headaches), and cortically spreading depression are seen neurophysiologically together in migraines. However, in spite of increasing information on migraine pathophysiology and various pieces of research, the underlying mechanisms of migraine attacks are still not completely understood. 
Gonadal hormones, especially estradiol, play a role in migraine formation. In women, where headaches are three or four times more common, migraine may be triggered by a sudden decrease in the plasma levels of estrogen in the premenstrual period (3). Neurobiological mechanisms related to the effects of estrogen on migraine are controversial. It has been shown to decrease especially in the trigeminal system nociception with estrogen in mice (4). It is known that migraine is two to three times more common in women than men. In women migraine is higher in the reproductive age where the serum estrogen level is highest, whereas it is lower before puberty and after the menopause (5). The results of studies in women indicate that migraine attacks are positively associated with the menstrual cycle (6). The results obtained from the studies show a positive relationship between migraine attacks and different serum estrogen levels. Estrogen plays an important role in the pathogenesis of migraine but its molecular basis is not well understood.

Additionally, it is thought that they have neuroprotective effects, although statins have a few side effects they might be a useful drug for curing neurodegenerative disorders. In addition to the cholesterol-lowering properties of statins, their antioxidant, antiinflammatory effects and also their effects on NO have been shown (7-11). Atorvastatin (AT), which is a member of the statin family, has been used because of its neuroprotective and anti-inflammatory effects in a variety of nervous system diseases $(9,12,13)$.

Systemic administration of nitroglycerin (NTG) to migraine patients typically causes aura-free attacks after a few hours but not in healthy volunteers $(14,15)$. NTG also increases the expression of neuronal nitric oxide (nNOS) in spinal trigeminal neurons (16). The mechanisms that explain how NTG and $\mathrm{NO}$ affect migraine are not known for certain. Headaches are affected by changes in estrogen levels during pregnancy and menopause $(17,18)$. The regulatory effects of estrogen on migraine are controversial. Systemic NTG administration activates nociceptors in the caudal spinal trigeminal nucleus in rats (19). NO stimulates the trigeminal $C$ and $A \delta$ afferents, and the second type of nociceptors is responsible for this stimulation. Calcitonin gene-related peptide (CGRP) is a key molecule in primary nociceptive afferents, released by NO mediated mechanisms in animals (20). CGRP increases in jugular blood during migraine attacks (21). Several studies are suggesting NO causes migraine attacks in migraine pathogenesis $(12,22,23)$.

It is known that the Wnt/ $\beta$-catenin signaling pathway is involved in brain development and neurodegenerative diseases. In a study it was shown that CGRP is able to regulate $\beta$-catenin signaling by induction of RNA synthesis of $\beta$-catenin (24). NO was shown to attenuate the $\beta$-catenin/TCF signal in colon cancer cells and $\beta$-catenin degradation mediated this event (25). This study is consistent with the possibility that upregulation of Wnt/ $\beta$-catenin may contribute to the macrocephaly associated with autism and some aspects of the behavioral phenotype (26). It was observed that NTG (10 mg/kg, s.c.) significantly increased plasma NO and CGRP concentrations and c-fos expression in the trigeminal nucleus caudalis (TNC) (27). NTG increases the expression of some key molecules such as c-fos (28-30) CGRP release increases c-fos expression (31). Increased serum calcium-binding protein B (S100B) concentration in patients with migraine has been reported $(32,33)$. Brain specific proteins are involved significantly in neuropathology due to intracellular and extracellular functions. Measurement of the astroglial protein $\mathrm{S100B}$, which is one of these proteins, especially in the serum, is used to show the blood brain barrier (BBB) damage index (34). It is reported that in a study of 151 patients with migraine that there was no difference between total antioxidant capacity (TAS) and total oxidant capacity (TOS) between patients and controls (35). Yilmaz et al. (36), reported that TOS levels increased in migraineurs compared to control, TAS levels did not change. Alp et al. (37) suggest that TOS is increased in migraine without aura, TAS is decreased. The results of the same study show that the vasoactive regulator is a new mechanism and the neurohormonal effect of CGRP is regulated by matrix metalloproteinase-2 (MMP-2) (38). In one review, statins are reported to lower cholesterol, increase endothelial nitric oxide (eNOS), disrupt $\beta$-amyloid production and serum apolipoprotein E levels, modulate learning associated receptors and MMPs, reduce reactive oxygen species, and increase cerebral blood flow (39). In this study, we aimed to investigate the effects of AT on migraine pathophysiology induced by NTG in ovariectomized female rats.

\section{MATERIALS AND METHODS}

\section{Animals}

Animal experiments Bezmialem University Foundation was approved by the Animal Care and Use Committee (Date: 29.10.2015, No: 2015/32). In the study, 42 3-month old adult Sprague Dawley female rats were placed in cages in groups of two or four in a temperature-controlled room $\left(22 \pm 3^{\circ} \mathrm{C}\right)$. Standard pellet and tap water were fed ad libitum.

\section{Experimental Procedure}

In order to minimize estrogen activity, ovaries of threemonth-old female rats were removed under ketamine (35 $\mathrm{mg} / \mathrm{kg}$ i.p) and xylazine (5 mg / kg i.p) anesthesia. A month later, 4 experimental groups were created. The 1st Group was the Control $(n=10)$ : Received a single dose saline $0,5 \mathrm{ml} / \mathrm{kg}$ intraperitoneally; The 2nd Group AT ( $\mathrm{n}=10)$ : Received $10 \mathrm{mg} / \mathrm{kg}$ AT intraperitoneally (Lipitor, Pfizer); The 3rd Group NTG $(n=11)$ : Received $10 \mathrm{mg} / \mathrm{kg}$ a single dose NTG (Glyceryl Trinitrate DBL 50 $\mathrm{mg} / 10 \mathrm{ml}$ Ampul, Orna) intraperitoneally; The 4th Group NTG and AT $(n=11)$ Intraperitoneally received single dose $10 \mathrm{mg} / \mathrm{kg}$ NTG followed by a single dose $10 \mathrm{mg} / \mathrm{kg}$ AT administration. Four hours after NTG or vehicle injections the brains of 3 rats in each group were removed and postfixed for structural histological and immunohistochemistry examinations. The brains of 7 rats in each group, were dissected for biochemical analysis. We observed pain symptoms immediately after the injection $(1,40)$.

\section{Light Microscopy}

Following the experimental study, blood samples from the heart were taken under anesthesia, the animals were decapitated, and 
the brains were quickly removed. The brains were fixed in $10 \%$ neutral formalin ( $\mathrm{pH}=7.2$ ) for 24 hours and embedded in paraffin using the routine paraffin method (41). $4 \mu \mathrm{m}$ thickness sections were stained with hematoxylin-eosin (HE) and examined for general histological appearance under a light microscope.

\section{Immunohistochemical Staining Procedure}

The tissue slices that were mounted on poly-L-lysine slides were air-dried and deparaffinized. The sections were immunohistochemically stained with iNOS (rabbit Pub Neomarker, RB-1605-P dilution 1: 100), eNOS(rabbit Pab Neomarker, RB-1711-P dilution 1: 100), nNOS (Santa Cruz, rabbit polyclonal, SC-648 dilution 1: 100) MMP-2 (Santa Cruz, mouse monoclonal, SC-7963 dilution 1: 100), $\beta$-catenin (Santa Cruz, mouse monoclonal, SC7963 dilution 1:200) as previously indicated (10). eNOS and MMP-2 $+4{ }^{\circ} \mathrm{C} 16$ hours and iNOS, nNOS and $\beta$-catenin reacted with tissue samples for one hour at room temperature. The peroxidase activity was demonstrated using a 3-amino-9-ethylcarbazole substrate kit (Lab Vision, TA-004-HAC) and the sections were counterstained with Mayer's haematoxylin. The control tissue sections were used as positive controls. Slides were photographed and examined using the Kameram 390CU Imaging system (Mikro System Ltd. Turkey).

\section{Biochemical Analysis}

Total brain samples were separated and homogenized in PBS. Homogenized samples and blood were centrifuged. c-fos, CGRP, $\beta$-catenin, S100B levels, total nitrite/nitrate levels, TAS and TOS in plasma and tissue homogenates were measured by using ELISA kits [Hangzhou Eastbiopharm-CK-E30032 for c-fos, E30375, CGRP., E91556, $\beta$-catenin., E91555, S100B., E10868, total nitrite/nitrate., Siemens ADVIA 1200, TAS (42) and Siemens ADVIA1200, TOS (43) as previously described.

\section{Statistical Analysis}

Values are reported as mean \pm SEM. Statistical analysis was performed using GraphPad Prism version 6,0 for Windows (GraphPad Software, San Diego, CA, USA). One-way ANOVA for repeated measurements with a Bonferroni post-hoc test was used for comparisons; $p$-value of $<0.05$ was considered statistically significant.

\section{RESULTS}

We weighed the animals at the beginning of experiment. The animals gained weight after one month compared to the time before ovariectomization. During the experimental time, painrelated symptoms such as decreased water and food intake, erection in the hairs, mastication movement, hump position, increase in susceptibility to pain were observed in previously determined pain criteria in NTG injected rats $(44,40)$.

\section{Histological Findings}

Histologically, all the experiment groups had expansions of the blood vessels in the brain, but it was more apparent in nitroglycerin-treated rats.

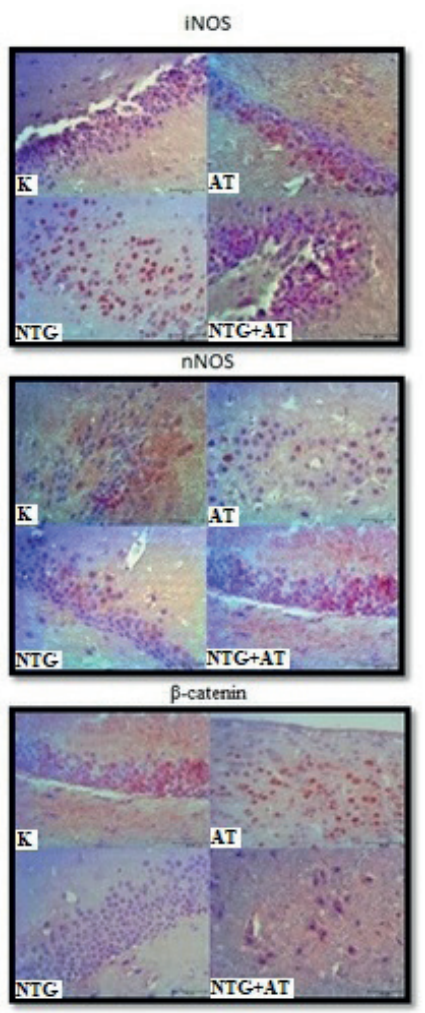

Figure 1. Immunohistochemical detection of iNOS, eNOS, nNOS, MMP-2 and $\beta$-catenin staining in total brain slices of rats in control (K) and experimental groups (NTG: Nitroglycerine, AT: Atorvastatin and NTG+AT: Nitroglycerine+Atorvastatin) (Bar:40 $\mu \mathrm{m})$. 
Table 1. Immunostaining intensity in total brain slices of rats in control and experimental groups were assessed by semiquantation of iNOS, eNOS, nNOS, MMP-2 and $\beta$-catenin on arbitrary four-point scale (NTG: Nitroglycerine, AT: Atorvastatin and NTG+AT: Nitroglycerine+Atorvastatin) $(0=$ not detectable, $+=$ weak,$++=$ mild and $+++=$ intense, $++++=$ high intense , $+++++=$ very high intense).

\begin{tabular}{lccccc}
\hline Groups & iNOS & eNOS & nNOS & MMP-2 & B-catenin \\
\hline Control & + & +++++ & +++++ & + & +++ \\
\hline AT & ++ & +++ & ++ & ++ & + \\
\hline NTG & +++++ & + & +++ & + \\
\hline NTG+AT & +++ & ++ & +++ & + & ++ \\
\hline
\end{tabular}

\section{Immunohistochemical Findings}

The results of MMP-2, iNOS, eNOS, nNOS and $\beta$-catenin immunohistochemical staining in the control and experimental groups rats are given in Figure 1. Reaction intensities of iNOS, eNOS, nNOS, MMP-2 and $\beta$-catenin positive cells in the total brain sections of rats in all groups are given in Table 1. According to our data, the reaction intensity in iNOS positive cells increased respectively in Control, AT, NTG+AT, NTG; the reaction in eNOS positive cells increased respectively in NTG, AT, NTG + AT, Control; the reaction in nNOS positive cells increased respectively in NTG, AT, NTG+AT, Control; the reaction in MMP-2 positive cells increased respectively in NTG, NTG+AT, Control, AT; the reaction in $\beta$-catenin positive cells increased respectively in NTG, NTG+AT, AT, Control.

\section{Biochemical Findings}

\section{c-fos Levels in Plasma Samples}

Plasma c-fos levels were detected in control group (4.068 \pm 0.911$)$, AT group $(4.111 \pm 0.675)$, NTG group (4.343 \pm 0.582$)$ and NTG+AT group (4.544 \pm 0.994$)$. NTG and NTG+AT groups had higher plasma c-fos levels than the control group, but it was not statistically significant (Figure 2).

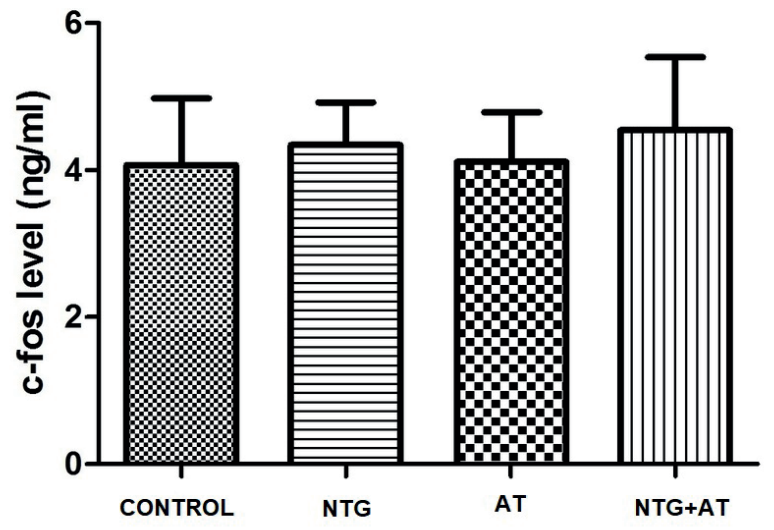

Figure 2. c-fos levels in plasma samples (NTG: Nitroglycerine, AT: Atorvastatin and NTG+AT: Nitroglycerine+Atorvastatin).

\section{c-fos Levels in Brain Homogenate Samples}

In the control group brain homogenate c-fos level was (57.596 \pm 17.571$)$, in the AT group $(48.887 \pm 18.252)$, in the NTG

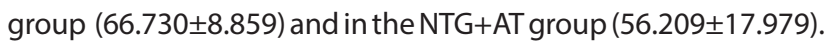

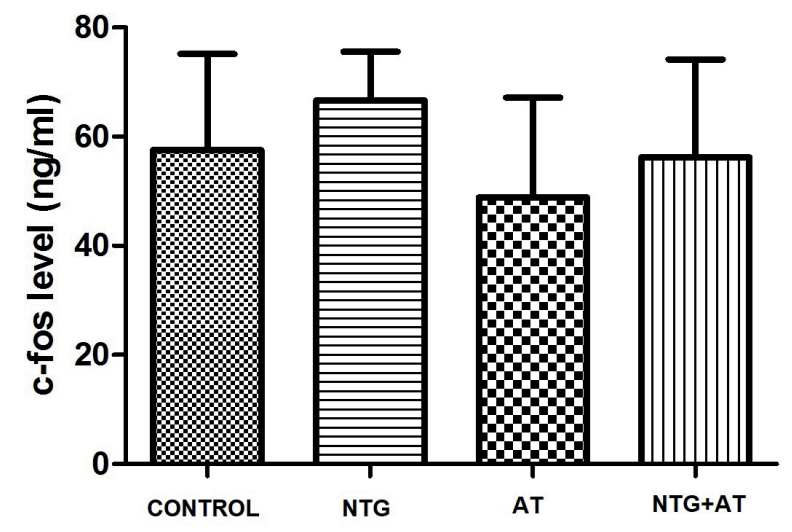

Figure 3. c-fos levels in brain homogenate samples (NTG: Nitroglycerine, AT: Atorvastatin and NTG+AT: Nitroglycerine+Atorvastatin).

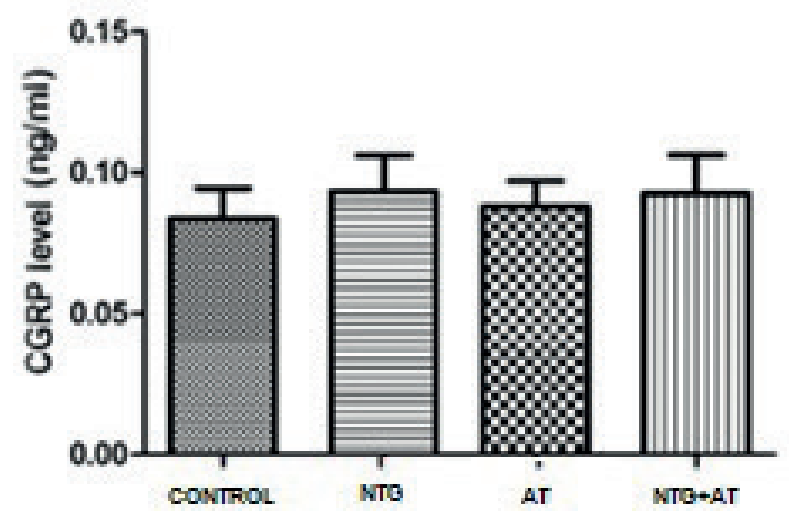

Figure 4. CGRP levels in plasma samples (NTG: Nitroglycerine, AT: Atorvastatin and NTG+AT: Nitroglycerine+Atorvastatin). 
Brain homogenate $c$-fos level was less in the AT group than the control group. c-fos level in brain homogenate was higher in the NTG group than in the control and was less NTG+AT group than in the NTG group, but it was not statistically significant (Figure 3).

\section{CGRP Levels in Plasma Samples}

Plasma CGRP level was in the control group (0.084 \pm 0.011$)$, AT group $(0.088 \pm 0.009)$, NTG group $(0.093 \pm 0.013)$ and NTG+AT group (0.011 \pm 0.014$)$. Plasma CGRP levels were higher in the AT and NTG groups than the control group, whereas it was low in the NTG+AT group but not statistically significant (Figure 4).

\section{CGRP Levels in Brain Homogenate Samples}

In the control group brain homogenate CGRP level was (1.267 \pm 0.294$)$, in the AT group (1.176 \pm 0.397$)$, in the NTG group $(1.394 \pm 0.285)$ and in the NTG+AT group (1.114 \pm 0.276$)$. Brain homogenate CGRP levels were found lower in AT and NTG+AT groups than control group whereas in NTG group was found

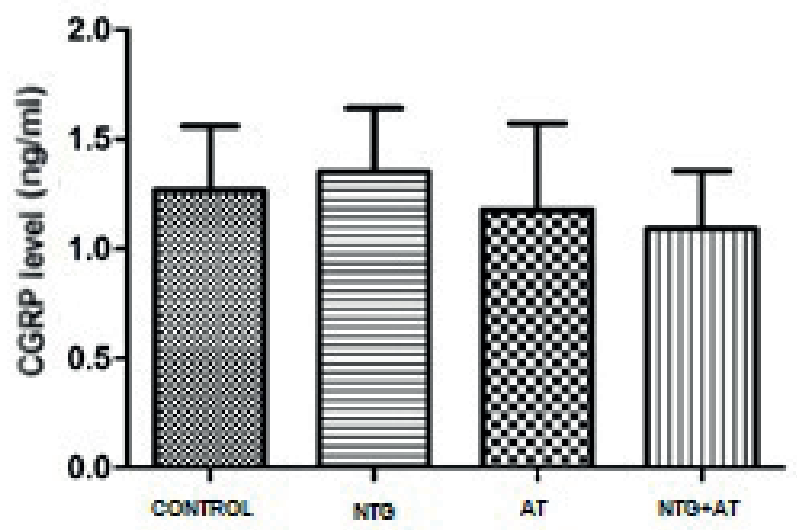

Figure 5. CGRP levels in brain homogenate samples (NTG: Nitroglycerine, AT: Atorvastatin and NTG+AT: Nitroglycerine+Atorvastatin).

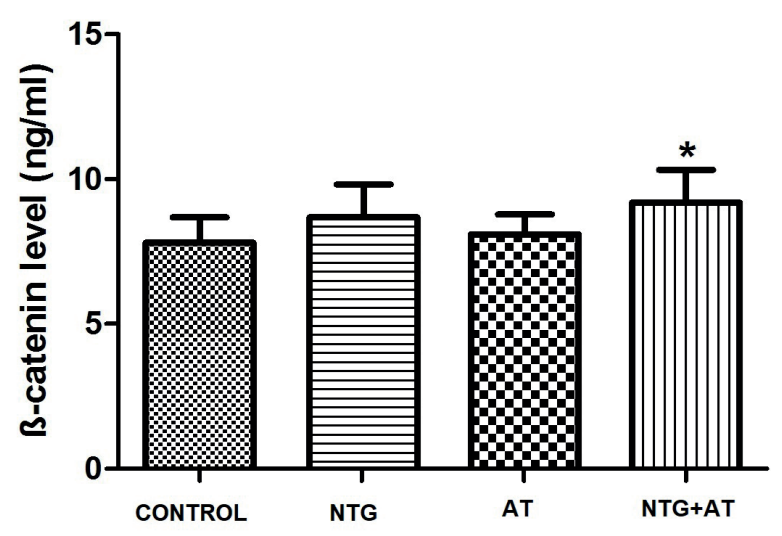

Figure 6. $\beta$-catenin levels in plasma samples. * Statistical significance compared to control group ( ${ }^{*} p<0.05$ ) (NTG: Nitroglycerine, AT: Atorvastatin and NTG+AT: Nitroglycerine+Atorvastatin). to be higher than the control group but it was not statistically significant (Figure 5).

\section{$\boldsymbol{\beta}$-catenin Levels in Plasma Samples}

In the control group plasma $\beta$-catenin level was (7.806 \pm 0.874$)$, in the AT group (8.089 \pm 0.689$)$, in the NTG group $(8.677 \pm 1.138)$ and in the NTG+AT group (9.125 \pm 1.130$)$. Plasma $\beta$-catenin levels in other experimental groups were found higher than the control group. In the plasma, NTG+AT administration increased significantly $\beta$-catenin levels $(p<0.05)$ (Figure 6).

\section{B-catenin Levels in Brain Homogenate Samples}

In the control group brain homogenate $\beta$-catenin levels was $(96.776 \pm 28.600)$, in the AT group $(93.569 \pm 28.549)$, in the NTG group $(105.874 \pm 25.722)$ and in the NTG+AT group $(87.018 \pm 22.421)$. Brain homogenate $\beta$-catenin levels were found lower in AT and NTG+AT groups than in the control

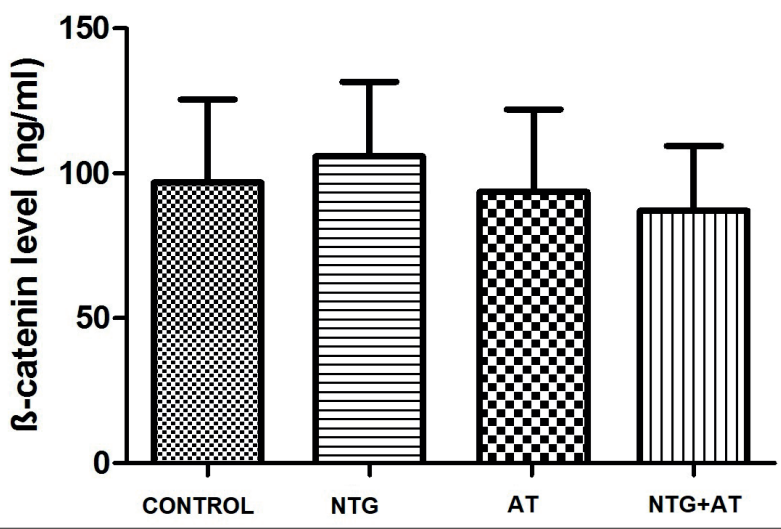

Figure 7. $\beta$-catenin levels in brain homogenate samples (NTG: Nitroglycerine, AT: Atorvastatin and NTG+AT: Nitroglycerine+Atorvastatin).

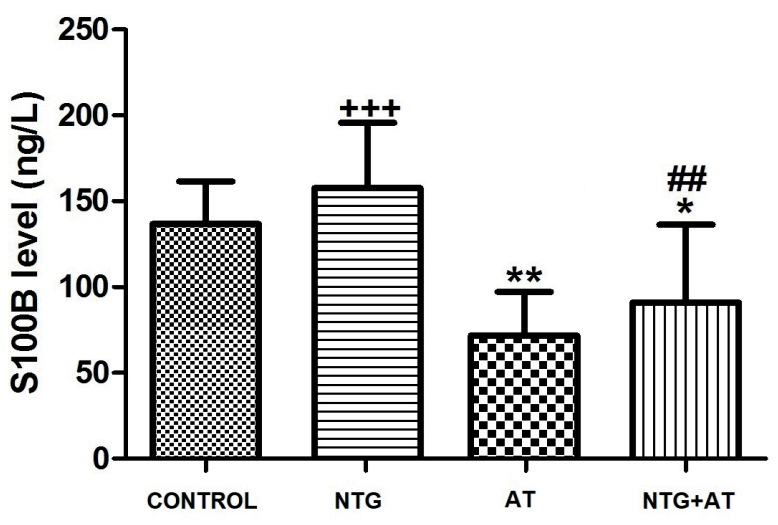

Figure 8. S100B levels in plasma samples. * Statistical significance compared to control group $\left({ }^{*} p<0.05,{ }^{* *} p<0.01\right)$, + Statistical significance compared to atorvastatin group $(+++p<0.001)$, \# Statistical significance compared to nitroglycerine group $(\# \# p<0.01)$ (NTG: Nitroglycerine, AT: Atorvastatin and NTG+AT: Nitroglycerine+Atorvastatin). 
group, in NTG group were found higher than in control group but it was not statistically significant (Figure 7).

\section{S100B Levels in Plasma Samples}

In the control group plasma S100B levels were (136.870 \pm 24.609$)$, in the AT group (71.837 \pm 25.420$)$, in the NTG group (157.528 \pm 38.172$)$ and in the NTG+AT group (90.924 \pm 45.498$)$. Plasma S100B levels were found to be significantly lower after administration of AT $(p<0.01)$ and NTG+AT $(p<0.05)$. Plasma S100B levels were significantly higher in the NTG group than the AT group $(p<0.001)$. Plasma S100B levels were found to be significantly lower after NTG+AT administration than NTG group $(p<0.01)$ (Figure 8).

\section{S100B Levels in Brain Homogenate Samples}

In the control group brain homogenate S100B level was $(1828.581 \pm 1370.250)$, in the AT group (2141.891 \pm 777.314$)$, in

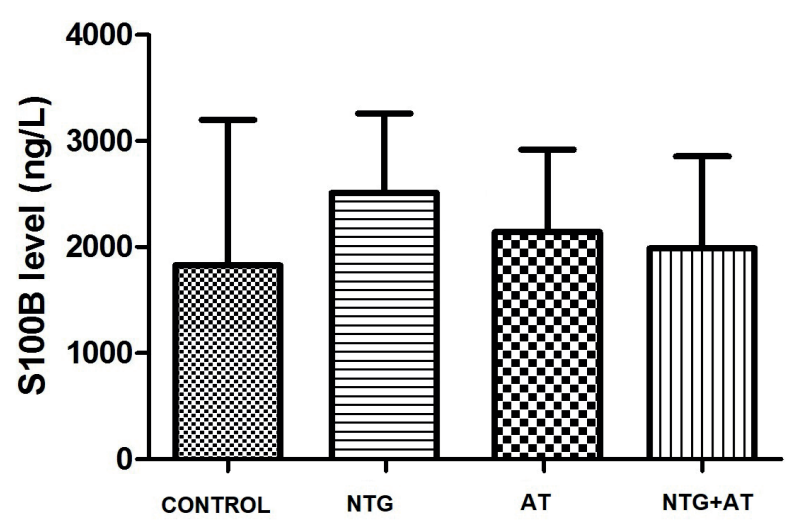

Figure 9. S100B levels in brain homogenate samples (NTG: Nitroglycerine, AT: Atorvastatin and NTG+AT: Nitroglycerine+Atorvastatin).

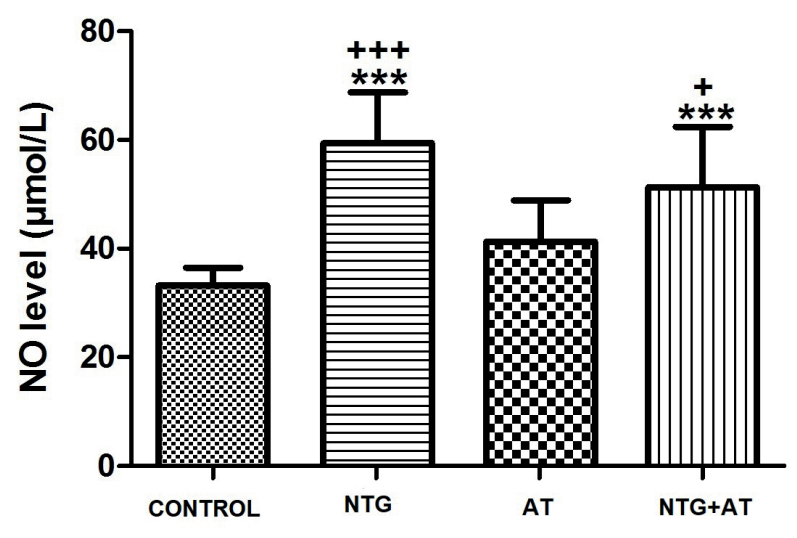

Figure 10. Total nitrite and nitrate levels in plasma samples. * Statistical significance compared to the control group $\left({ }^{* * *} p<0.001\right)$, + statistical significance compared to the atorvastatin group $(+p<0.05,+++p<0.001)$ (NTG: Nitroglycerine, AT: Atorvastatin and NTG+AT: Nitroglycerine+Atorvastatin). the NTG group (2510.610 \pm 746.165$)$ and in the NTG+AT group (1989.955 \pm 865.747$).$ S100B levels in brain homogenate samples were found higher in AT, NTG and NTG+AT groups compared to the control group. In addition, S100B levels in brain homogenate were found to be lower in NTG+AT group compared to the NTG group but it was not statistically significant (Figure 9).

\section{Total Nitrite and Nitrate Levels in Plasma Samples}

Plasma total nitrite and nitrate levels were detected in the

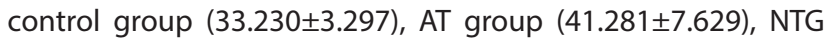

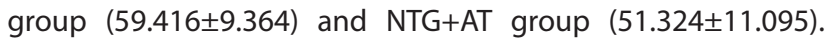
In the plasma samples, NTG and NTG+AT administration significantly increased the total nitrite and nitrate levels grade compared to the control group and also compared to the AT group $(p<0.001)$. Total nitrite and nitrate levels in plasma samples was found lower in NTG+AT group than NTG group but there was no statistically significant difference (Figure 10).

Total Nitrite and Nitrate Levels in Brain Homogenate Samples Brain homogenate total nitrite and nitrate levels were detected in the control group (295.326 \pm 68.460$)$, AT group (401.047 \pm 90.322$)$, NTG group (676.549 \pm 141.254$)$ and NTG+AT group (456.802 \pm 96.525 ). Total nitrite and nitrate levels in NTG $(p<0.001)$ and NTG+AT $(p<0.05)$ were found significantly higher than the control group. Total nitrite and nitrate levels in NTG group were found to be significantly higher than the AT group

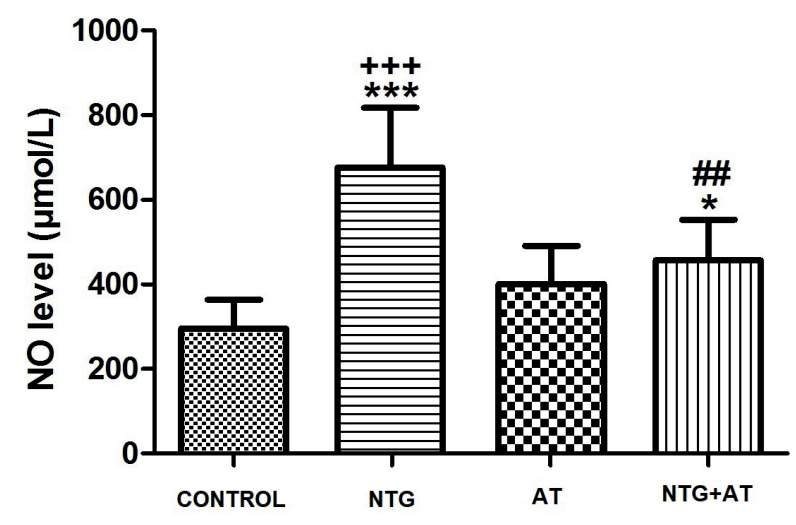

Figure 11. Total nitrite and nitrate levels in brain homogenate samples. * Statistical significance compared to control group $\left({ }^{*} p<0.05,{ }^{* * *} p<0.001\right),+$ Statistical significance according to atorvastatin group $(+++p<0.001)$, \# Statistical significance compared to the nitroglycerin group (\# $p<0.01$ ) (NTG: Nitroglycerine, AT: Atorvastatin and NTG+AT: Nitroglycerine+Atorvastatin).

$(p<0.01)$, whereas in the NTG group (after AT administration) these were found significantly lower $(p<0.01)$ (Figure 11).

\section{TAS Levels in Plasma Samples}

In the control group plasma TAS level was (1.232 \pm 0.095$)$, in the AT group (1.222 \pm 0.113$)$, in the NTG group (1.1155 \pm 0.047$)$ and in the NTG+AT group (1.107 \pm 0.089$)$. TAS levels in plasma samples in NTG+AT group were found to be significantly lower 


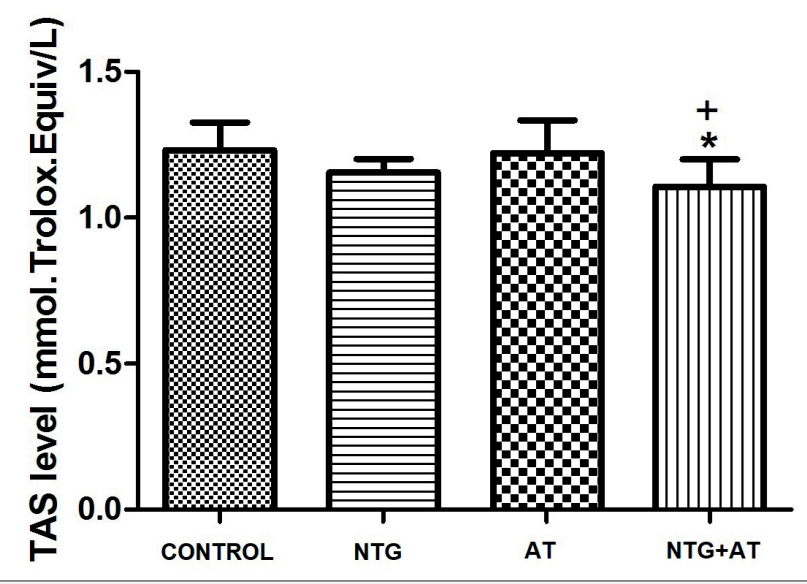

Figure 12. TAS levels in plasma samples. * Statistical significance compared to control group $\left({ }^{*} \mathrm{p}<0.05\right),+$ Statistical significance compared to the atorvastatin group $(+p<0.05)$ (NTG: Nitroglycerine, AT: Atorvastatin and NTG+AT: Nitroglycerine+Atorvastatin).

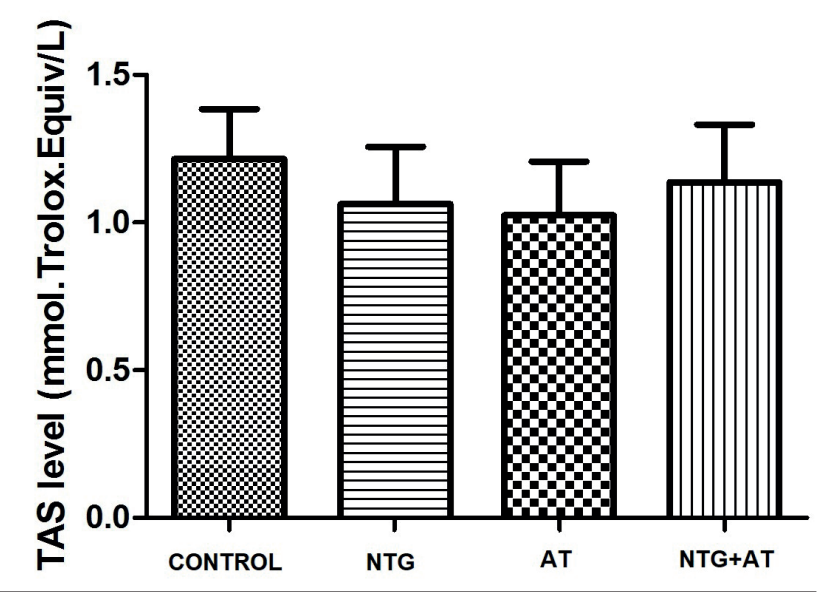

Figure 13. TAS levels in brain homogenate samples (NTG: Nitroglycerine, AT: Atorvastatin and NTG+AT: Nitroglycerine+Atorvastatin).

compared to the control and AT groups $(p<0.05)$, whereas the NTG+AT group was found lower than the NTG group, but there was no statistically significant difference (Figure 12).

\section{TAS Levels in Brain Homogenate Samples}

In the control group, brain homogenate TAS levels were (1.215 \pm 0.169$)$, in the AT group (1.025 \pm 0.182$)$, in the NTG group (1.063 \pm 0.194$)$ and in the NTG+AT group (1.137 \pm 0.195$)$. TAS levels in brain homogenate samples in AT, NTG and NTG+AT groups were found to be lower than the control. Also TAS levels in brain homogenate samples in NTG+AT was found higher than NTG but there was no statistically significant difference (Figure 13).

\section{TOS Levels in Plasma Samples}

In the control group, plasma TOS levels were (12.332 \pm 1.619$)$, in the AT group (12.378 \pm 1.457$)$, in the NTG group (12.765 \pm 1.627$)$ and in the NTG+AT group (11.534 \pm 1.873$)$. Plasma TOS levels in

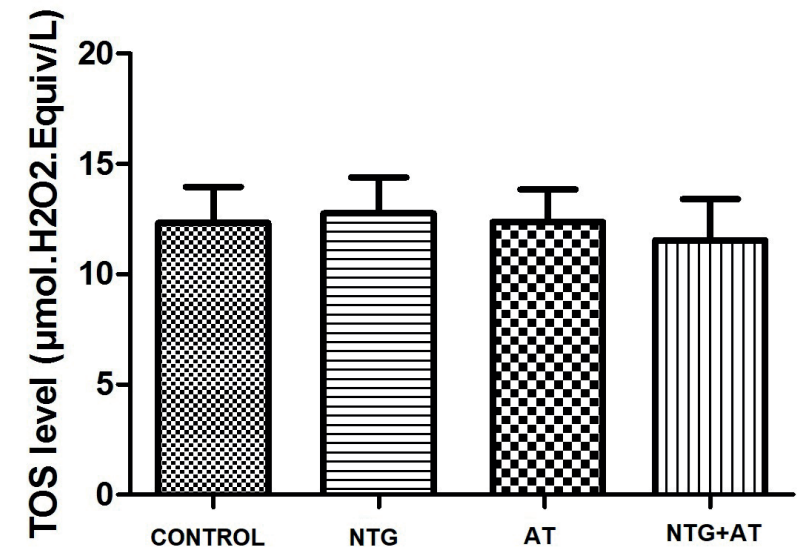

Figure 14. TOS levels in plasma samples (NTG: Nitroglycerine, AT: Atorvastatin and NTG+AT: Nitroglycerine+Atorvastatin).

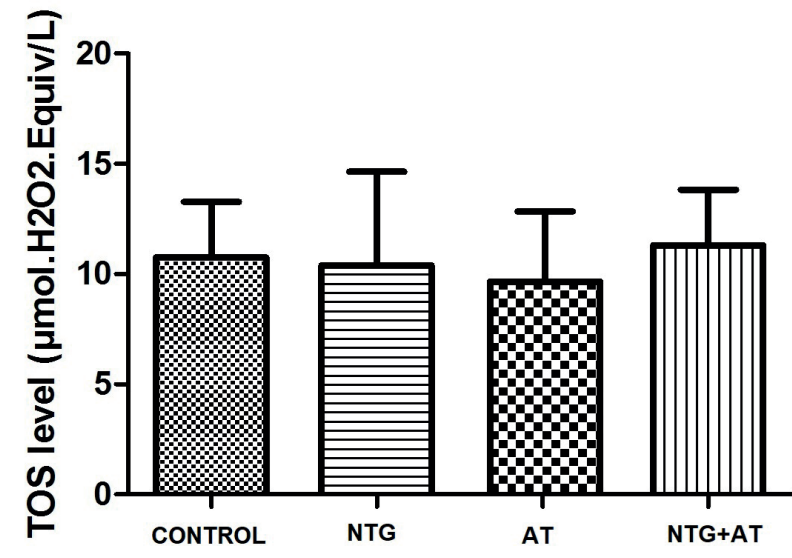

Figure 15. TOS levels in brain homogenate samples (NTG: Nitroglycerine, AT: Atorvastatin and NTG+AT: Nitroglycerine+Atorvastatin).

NTG were higher than the control and AT groups, whereas in NTG+AT, the levels were found lower than NTG, but there was no statistically significant difference (Figure 14).

\section{TOS Levels in Brain Homogenate Samples}

In the control group, brain homogenate TOS levels were (10.750 \pm 2.525$)$, in the AT group (9.655 \pm 3.188$)$, in the NTG group $(10.397 \pm 4.242)$ and in the NTG+AT group (11.301 \pm 2.518$)$. TOS levels in NTG+AT were found higher than the control, but there was no statistically significant difference (Figure 15).

\section{DISCUSSION}

Migraine is a disease characterized by a severe, recurrent headache associated with nausea, vomiting and photophobia. In this study, we investigated whether or not pain developed in the experimental migraine model resulting from NTG administration in ovariectomized female rats and whether there was a protective effect of AT on histological and biochemical changes in rats. To this end, some proteins and NOS levels such 
as CGRP and, c-fos which play a role in migraine in both brain homogenates and plasma specimens were investigated. Also, levels of $\mathrm{S100B}$, a marker of brain damage in plasma and total brain homogenates were measured.

Although the mechanism is still not very clear, the chemical vasodilators that trigger migraines are used in the formation of the neuronal activation response and in the observation of vascular changes. It was used to form an experimental migraine, and the NO donor NTG cause neuronal activation at the level of the trigeminal nucleus caudalis and midbrain (45). NTG increases expression of some key molecules such as NF-KB (46), c-fos (28-30), nNOS (47-50) in TNC where most trigeminovascular nociceptive afferents $(51,52)$. The vasodilator effect of NTG occurs 2-6 hours after administration (53). It has been shown that attacks of a headache in migraine patients are triggered 4 to 6 hours after intravenous administration of NTG. In experimental studies, a dose of NTG (10 mg / kg) used which was higher than the equivalent dose used to induce migraine in humans $(1,12)$. In our study, ovariectomized female rats were given i.p. administered $10 \mathrm{mg} / \mathrm{kg}$ NTG. (40) and in contrast to Erdener and Dalkara (1) we observed pain symptoms immediately after this injection (31). In our study, it was observed that rats hind extremities were held low on the floor, they had difficulty walking, and they searched for a comfortable position. Furthermore, they experienced itching, abnormal sleep, erection of hairs, and an increased sensitivity to sound. These symptoms indicate that NTG causes pain and migraine in rats. NO donors and other potent vasodilators cause an immediate headache and vasodilation of cranial blood vessels in migraine patients and volunteers and animal studies $(54,55)$. Our findings of pain are parallel to these studies. During migraine, the TNC is warned and remains over active for a long time. Perivascular nociceptive afferents are activated, vasoactive mediators (CGRP, substance $P$, neurokinin $A$ and pituitary adenylate cyclase-activating polypeptide-PACAP) are released and mast cell degranulation causes neurogenic inflammation in the dura mater (1). Also, CGRP plays an important role in migraine pathophysiology, leading to cranial vasodilatation and facilitation of nociception (56). The key role of CGRP in many regions within the trigeminal system indicates that it participates in migraine pathophysiology $(57,58)$. In addition, it is suggested that CGRP concentration increases in serum and saliva of patients suffering from acute migraine and headache (58-60). We used ovariectomized female rats in this study and waited 30 days to reset the estrogen (61). Estrogen increases the activity of NOS, NO levels are therefore higher in women. The presence of rich estrogen receptors in the trigeminal system supports that estrogen is directly related to pain. On the other hand, changes in estrogen level have been shown to cause changes in the amount of molecules that are important in the transmission of pain signal such as serotonin and gamma-aminobutyric acid. Recently, changes in depression in the presence of estrogen and progesterone may be related to the frequency of increased migraine aura and to facilitating synaptic transmissions of sexual hormones (62). In a study conducted, it was shown that removal of ovaries reduced
CGRP levels (63).However, the neurobiological mechanisms related to the migraine regulatory effects of estrogens are controversial. In our study CGRP statistically insignificantly increased in both plasma and brain homogenate samples in the NTG group compared to the control group which may be due to the absence of ovaries and thus the absence of estrogen.

Studies using monoclonal CGRP or CGRP receptor antagonists in migraine therapy are promising (64). It has been reported that the effect of NO and CGRP on migraine is very important and that NOS inhibition significantly inhibits migraine attacks (65). Plasma nitrite and nitrate, CGRP and c-fos expression have been shown to increase with NTG administration (27). In the same study, it is stated that the effect of Gas-D obtained from Tianma, which has been used for a long time in China for treatment, is shown by decreasing plasma nitrite/nitrate and CGRP level. In our study, a significant $(p<0.01)$ reduction of $\mathrm{NO}$ in the brain homogenate samples of the treatment group supports that AT may be useful for migraine pathology. However, we believe that there is a need for more detailed studies on this subject.

By stimulating the trigeminal vasculature, CGRP is released and c-fos expression is increased (31). The activation of the c-fos gene begins within 5 minutes of the stimulation and continues until the end of the stimulation (1). Trigeminal nerve activation was demonstrated by increased expression of ipsilateral c-fos in the caudal trigeminal nucleus of CSD (66). It is indicated that c-fos expression is maximal after 4 hours of NTG injection and animals are perfused after 4 hours from $10 \mathrm{mg} / \mathrm{kg}$ NTG injection (67). In our study, there was no significant difference between c-fos levels in either plasma or homogenate samples. Given that CGRP leads to a c-fos increase, the lack of estrogen in our study due to the use of ovariectomized rats can explain the fact that the non-significant CGRP increase is not sufficient enough to increase c-fos levels. Considering that c-fos protein can be detected immunohistochemically in neuronal nuclei for approximately 30 minutes post-stimulation and has a half-life of 2 hours after the end of the stimulation (1), a nonsignificant increase in c-fos levels may be due to the termination of the experiment after 4 hours (68). $\beta$-catenin is one of the active paths in brain development and neurodegenerative diseases. $\beta$-catenin has been shown to play an important role in the expansion of the precursor pool, in neuronal movement and in cortical lamination (69). In one study, the relationship between the acceleration of seizure induction for the first time after ischemia and the signal pathway of astrocytic $\beta$-catenin was demonstrated. Activation or inhibition of the Wnt/ $\beta$-catenin pathway after pentylenetetrazole administration has been reported to be effective on c-fos expression (70). Prévotat et al. (25) indicated that NO is effective by reducing the amount of $\beta$-catenin in colon cancer. In our study, the plasma $\beta$-catenin levels were significantly increased in NTG+AT group compared to the control group $(p<0.05)$, whereas in brain homogenates AT and NTG+AT groups were decreased compared to the control group but it was not statistically significant. In recent years, $\beta$-catenin effects of anticonvulsants in different brain regions have been studied. Antiepileptic and antidepressant drugs are used in the treatment of migraine (71). In the rats exposed to valproic acid, 
an accumulation of $\beta$-catenin was shown in the cytoplasm and nucleus (26). We have shown the anticonvulsant effect of AT in our previous studies (9). In this study, unlike valproic acid, AT administration resulted in a nonsignificant decrease in $\beta$-catenin levels in brain homogenate, however $\beta$-catenin levels significantly increased in plasma. This increase might be the result of the arrival of $\beta$-catenin from different sources. These differences may be due to the animal species used, the lack of estrogen, the amount of the substance given, and the duration of the application.

BBB injury is responsible for the pathogenesis of cerebrovascular diseases. In migraine patients an increase in the concentration of serum S100B has been reported $(32,33)$. Brain-specific proteins are involved in many neuropathologies due to intracellular and extracellular functions. The measurement of astroglial protein $\mathrm{S} 100 \mathrm{~B}$, which is one of these proteins, especially in serum is essential in showing BBB damage index (34). Yilmaz et al, (2011) showed in their study that patients with migraine-without aura had significantly higher ictal serum levels of S100B and NSE than control subjects. Whereas in the interictal phase, there was a significant increment only in S100B levels compared to controls. These results show that Increased interictal serum levels of S100B might point to an insidious and slow damaging process in a migraine patient (33). The use of drugs used in the treatment of migraine with aura is controversial (72). NTG administration in our study increased the levels of $\mathrm{S100B}$ in plasma samples, compared to the control group. In animals treated with NTG+AT, plasma S100B levels were significantly lower compared to NTG group $(p<0.01)$. S100B levels in brain tissue homogenate samples in NTG+AT group, compared to NTG group, there was a nonsignificant decrease. Independent of cholesterol-lowering effects of statins in recent years is reported to have neuroprotective and anti-inflammatory effects on neurodegenerative diseases as an antioxidant (7). In our previous study we determined the healing effects of AT on epileptic seizures and memory disorders (9). Our findings showed that atorvastatin could inhibit astroglial activity by its antiinflammatory effect and showed a protective effect towards BBB and so reduce the risk of possible neurodegenerative diseases in rats with migraine. Our results will provide a significant contribution to studies in this field.

$\mathrm{NO}$ is a small gas molecule that plays various roles in the central nervous system (73). Statins are reported to reduce iNOS activity and increase eNOS expression to reduce the inflammatory reaction involving neuropathic pain $(74,75)$. Also, statins show neuroprotective effects by decreasing microglial and astrocyte activation and cytokine release (76). In our study, we investigated the distributions of eNOS, nNOS and iNOS in sections the brains of control and experimental animals. In this study, we found that while eNOS decreased, iNOS increased in migraine. With the treatment of AT, we found that iNOS decreased and eNOS increased. Also, nNOS has been shown to be functional in many diseases based on migraine, strokes, epilepsy, Huntington's disease and disorders of the nervous system (77). Experimental and clinical studies demonstrated that statins have protective effects in addition to reducing cholesterol. For example statins, control endothelial function through cholesterol-dependent and independent mechanisms or pleiotropic effects and provide eNOS expression (78). These studies support our findings of NOS reactions. In our study, we also measured the total nitrite-nitrate amount in plasma and brain homogenate by ELISA method. Plasma NO levels increased significantly in NTG group compared to the control group but decreased in NTG+AT group compared to NTG. NO levels in brain homogenates increased statistically significantly in NTG group compared to the control group. Brain homogenate NO levels increased in NTG compared to the control group but in NTG+AT group were significantly decreased compared to NTG. Continuous release of cytokines, prostanoids, and NO into the subarachnoid space causes long-term activation of perivascular nociceptive trigeminal afferents in the pia mater (79). As a donor of NO, it is suggested that NTG may affect migraine attacks and may be used to experimentally investigate the mechanisms in migraine pathophysiology $(22,80)$. These studies support our results. In animal models, it is suggested that drugs that are effective in the treatment of migraine are effective by raising the threshold of initiation of cortical spreading depression (60). Headaches vary depending on ovulation, menstruation, pregnancy, menopause, drugs, reproductive cycle $(5,81)$. It is suggested that these effects are caused by the rich estrogen receptors on the trigeminal system of estrogen (82). Moreover, it has been observed that estrogen levels may cause changes in molecules such as serotonin and gamma-aminobutyric acid which are involved in pain signal transmission (83). Pronociceptive effects of estrogens have been shown.

In recent studies, it has been suggested that estrogen and progesterone increase the frequency of migraine aura by facilitating synaptic transmission (62). In our study, we aimed to remove the possible stimulant effect of estrogen by using ovariectomized rats. Our results showed that the adverse effects of NTG-induced could be improved by AT administration. This conclusion supports the theory that AT may be used as an alternative component in the treatment of migraine.

Migraine is known as a long-lasting neurological disease, but its physiopathology is not clear. Studies support the relationship between migraine and oxidative stress. It was reported that in a study of 151 patients with migraine there was no difference between TAS and TOS between patients and controls (35). It was showed that NO levels elevated in plasma and platelets during migraine (84-86). NO, and its metabolites have been reported to be oxidative stress markers in migraine patients (87). When we compared plasma TAS and TOS levels in our study, we did not find a significant difference. Our results are consistent with the result of other studies. TAS is a method used to detect antioxidant activity. Yilmaz et al. (36), reported that TOS levels increased in migraineurs compared to control, TAS levels did not change. Alp et al. (37) suggest that whileTOS is increased in migraines without aura, TAS is decreased. In another study, antioxidant capacity was found to be lower in patients with chronic migraine. Chronic migraine is associated with mitochondrial dysfunction, and is effective in the balance between oxidative and antioxidant status; it is not 
clear how the drugs used in migraine affect the oxidative stress parameters $(88,89)$. In our study, there was an increase in TOS levels in the migraine group compared to the control group but it was not statistically significant. There was no significant change in TAS levels between the groups. Our results are consistent with the literature in this area. We found a significant decrease in antioxidant capacity in the plasma samples of the treatment group. Results of studies related to oxidant and antioxidant system failure in migraine patients are also different from each other. Further detailed studies are needed for a better understanding of what happens during migraine attacks, migraines and follow on work on oxidant and antioxidant balance.

The trigeminovascular system is located outside the BBB and has an important role in migraine pathology. Therefore, the new CGRP drugs that are effective at treating migraines target the trigeminovascular system $(38,90)$. It has been suggested that vascular MMP-2 breaks down endogenous CGRP and induces vasoconstriction. The results of the same study show that vasoactive regulatory is a new mechanismand the neurohormonal effect of CGRP is regulated by MMP-2 (38). In our study, brain sections were stained with MMP-2 immunohistochemically. The distribution of MMP-2 positive cells was similar in the control, NTG and NTG+AT groups. MMP-2 positive cells were slightly higher in the AT-treated group than in the other groups. In one review, statins are reported to lower cholesterol, increase eNOS, disrupt $\beta$-amyloid production and serum apolipoprotein E levels, modulate learning-associated receptors and MMPs, reduce reactive oxygen species, and increase cerebral blood flow (39). In our study, we did not find any significant effect of the NTG and AT on the MMP-2. These results may be due to the short duration of application of the substances we used.

\section{CONCLUSION}

In conclusion, histological and biochemical changes in the migraine model developed with nitroglycerin in this study and atorvastatin that we applied on ovariectomized rats for treatment was determined to have positive effects on this damage. Histologically, the expansion of blood vessels in the brains of rats administered with nitroglycerin was seen to be more apparent. Studies on the association between migraine sufferers and the oxidant-antioxidant system failure show disparities. We also compared the level of serum TAS and TOS, we observed no significant difference. We can say that AT generates these effects by increasing eNOS and nNOS levels, reducing the production of iNOS and S100B, and reducing the levels of CGRP and c-fos in sample brain homogenates. Also, our findings showed that AT could inhibit astroglial activity by its anti-inflammatory effect and showed a protective effect towards BBB and so reduce the risk of possible neurodegenerative diseases in rats with migraine. Our results will provide a significant contribution to studies in this field.

Peer-review: Externally peer-reviewed.

Author Contributions: Conception/Design of study: K. A. D., A. C. H.; Data Acquisition: K. A. D., A. C. H.; Data Analysis/Interpretation:
K. A. D., A. C. H.; Final Approval and Accountability: K. A. D.; Drafting Manuscript: K. A. D.; Critical Revision of Manuscript: K. A. D..

Acknowledgement: We thanks to Facultad Ciencias Exactas Naturales, Universidad Nacional Catamarca (FACEN-UNCA) and Instituto Biodiversidad Neotropical (IBN-UNT) by facilities and other assistances. For the loan of specimens we thank to J. Andreoli Bize (FACEN).

Conflict of Interest: The author has no conflict of interest to declare.

Financial Disclosure: Istanbul University Scientific Research Projects Coordination Unit, 50185.

\section{REFERENCES}

1. Erdener SE, Dalkara T. Modelling headache and migraine and its pharmacological manipulation. Br J Pharmacol 2014; 171(20): 4575-94.

2. Fischer M, Wille G, Klien S, Shanib H, Holle D, Gaul C, et al. Brainderived neurotrophic factor in primary headaches. J Headache Pain 2012; 13(6): 469-75.

3. Somerville BW. Estrogen-withdrawal migraine. I. Duration of exposure required and attempted prophylaxis by premenstrual estrogen administration. Neurology 1975; 25(3): 239-44.

4. Multon S, Pardutz A, Mosen J, Hua MT, Defays C, Honda S, et al. Lack of estrogen increases pain in the trigeminal formalin model: a behavioural and immunocytochemical study of transgenic ArKO mice. Pain 2005; 114(1-2): 257-65.

5. Scharfman HE, MacLusky NJ. Estrogen-growth factor interactions and their contributions to neurological disorders. Headache 2008; 48 Suppl 2: S77-89.

6. Merki-Feld GS, Imthurn B, Langner R, Seifert B, Gantenbein AR. Positive effects of the progestin desogestrel $75 \mu \mathrm{g}$ on migraine frequency and use of acute medication are sustained over a treatment period of 180 days. J Headache Pain 2015; 16: 522.

7. Goldstein LB. Statins and ischemic stroke severity: cytoprotection. Current Atherosclerosis Reports 2009; 11(4): 296-300.

8. Hasanein P, Shahidi S. Effects of combined treatment with vitamins $\mathrm{C}$ and $\mathrm{E}$ on passive avoidance learning and memory in diabetic rats. Neurobiology of Learning and Memory 2010; 93(4): 472-8.

9. Üzüm G, Akgün-Dar K, Aksu A. The effects of atorvastatin on the development of Pentylenetetrazole induced kindling, related learning and memory impairments. Epilepsy \& Behavior 2010; 19 (3): 284-9.

10. Akgün-Dar K, Kapucu A, Acar S, Üzüm G. Evaluation of Antiepileptogenic Effect of Atorvastatin on Development of Pentylenetetrazole Induced Kindling in Rats: The Responsibility of Inducible Nitric Oxide Synthase and Metalloproteinase 2. Turkiye Klinikleri J Med Sci 2013; 33: 995-1006.

11. Bahçekapılı N, Akgün-Dar K, Albeniz I, Kapucu A, Kandil A, Yağız O, et al. Erythropoietin pretreatment suppresses seizures and prevents the increase in inflammatory mediators during pentylenetetrazole induced generalized seizures. Int J Neurosci 2014; 124(10): 762-70.

12. Yin Z, Fang $Y$, Ren $L$, Wang $X$, Zhang A, Lin J, et al. Atorvastatin attenuates NF-kappaB activation in trigeminal nucleus caudalis in a rat model of migraine. Neurosci Lett 2009; 465(1): 61-5.

13. Sarrouilhe D, Dejean C, Mesnil M. Involvement of gap junction channels in the pathophysiology of migraine with aura. Front Physiol 2014; 5: 78.

14. Sicuteri F, Del Bene E, Poggioni M, Bonazzi A. Unmasking latent 
dysnociception in healthy subjects. Headache 1987; 27(4): 180-5.

15. Olesen J, Iversen HK, Thomsen LL. Nitric oxide supersensitivity: a possible molecular mechanism of migraine pain. Neuroreport 1993; 4(8): 1027-30.

16. Pardutz A, Krizbai I, Multon S, Vecsei L, Schoenen J. Systemic nitroglycerin increases nNOS levels in rat trigeminal nucleus caudalis. Neuroreport 2000; 11(14): 3071-5.

17. Marcus DA. Interrelationships of neurochemicals, estrogen, and recurring headache. Pain 1995; 62(2): 129-39.

18. Silberstein SD, Merriam GR. Physiology of the menstrual cycle. Cephalalgia 2000; 20(3): 148-54.

19. Tassorelli C, Joseph SA. Systemic nitroglycerin induces Fos immunoreactivity in brainstem and forebrain structures of the rat. Brain Res 1995; 682(1-2): 167-81.

20. Garry MG, Walton LP, Davis MA. Capsaicin-evoked release of immunoreactive calcitonin gene-related peptide from the spinal cord is mediated by nitric oxide but not by cyclic GMP. Brain Res 2000; 861(2): 208-19.

21. Goadsby PJ, Edvinsson L, Ekman R. Vasoactive peptide release in the extracerebral circulation of humans during migraine headache. Ann Neurol 1990; 28(2): 183-7.

22. Greco R, Tassorelli C, Mangione AS, Smeraldi A, Allena M, Sandrini $G$, et al. Effect of sex and estrogens on neuronal activation in an animal model of migraine. Headache 2013; 53(2): 288-96.

23. Arakaki X, Galbraith G, Pikov V, Fonteh AN, Harrington MG. Altered brainstem auditory evoked potentials in a rat central sensitization model are similiar to those in migraine. Brain Res 2014; 1563: 110-21.

24. MrakE, Guidobono F, Moro G, Fraschini G, Rubinacci A, Villa I. Calcitonin gene-related peptide (CGRP) inhibits apoptosis in human osteoblasts by $\beta$-catenin stabilization. J Cell Physiol 2010; 225(3): 701-8.

25. Prévotat $L$, Filomenko $R$, Solary $E$, Jeannin JF, Bettaieb A. Nitric oxide-induced down-regulation of beta-catenin in colon cancer cells by a proteasome-independent specific pathway. Gastroenterology 2006; 131(4): 1142-52.

26. Wang Z, Xu L, Zhu X, Cui W, Sun Y, Nishijo H, et al. Demethylation of specific $W n t / \beta$-catenin pathway genes and its upregulation in rat brain induced by prenatal valproate exposure. Anat Rec (Hoboken) 2010; 293(11): 1947-53.

27. Wang PH, Zhao LX, Wan JY, Zhang L, Mao XN, Long FY, et al. Pharmacological characterization of a novel gastrodin derivative as a potential anti-migraine agent. Fitoterapia 2016; Mar; 109: 52-7.

28. Offenhauser N, Zinck T, Hoffmann J, Schiemann K, Schuh-Hofer S, Rohde W, et al. CGRP release and c-fos expression within trigeminal nucleus caudalis of the rat following glyceryltrinitrate infusion. Cephalalgia 2005; 25(3): 225-36.

29. Tassorelli R, Greco P, Morazzoni A, Riva G, Sandrini G, Nappi G. Parthenolide is the component of tanacetum parthenium that inhibits nitroglycerin-induced Fos activation: studies in an animal model of migraine. Cephalalgia 2005; 25(8): 612-21.

30. Knyihár-Csillik E, Toldi J, Mihály A, Krisztin-Péva B, Chadaide Z, Németh $H$, et al. Kynurenine in combination with probenecid mitigates the stimulation-induced increase of c-fos immunoreactivity of the rat caudal trigeminal nucleus in an experimental migraine model. J Neural Transm (Vienna) 2007; 114(4): 417-21.

31. Zhu X, Han Y, Xiong W, Liu W, Lu S, Li J, et al. Effects of heating coagulation of middle meningeal artery on plasma CGRP level and c-fos expression in migraine rat triggered by nitroglycerin. Neurol Sci 2011; 32(4): 589-94.

32. Teepker M, Munk K, Mylius V, Haag A, Möller JC, Oertel WH, et al. Serum concentrations of s100b and NSE in migraine. Headache 2009; 49(2): 245-52.
33. Yilmaz N, Karaali K, Ozdem S, Turkay M, Unal A, Dora B. Elevated $S 100 B$ and neuron specific enolase levels in patients with migraine-without aura: evidence for neurodegeneration? Cell Mol Neurobiol 2011; 31(4): 579-85.

34. Steinacker $P$, Weidehaas $K$, Cepek L, Feneberg E, Kretzschmar HA, Otto $M$. Influence of the blood-CSF-barrier function on S100B in neurodegenerative diseases. Acta Neurol Scand 2013; 128(4): 24956.

35. Eren $Y$, Dirik E, Neşelioğlu S, Erel Ö. Oxidative stress and decreased thiol level in patients with migraine: cross-sectional study. Acta Neurol Belg 2015; 115(4): 643-9.

36. Yilmaz N, Aydin O, Yegin A, Tiltak A, Eren E. Increased levels of total oxidant status and decreased activity of arylesterase in migraineurs. Clin Biochem 2011; 44(10-11): 832-7.

37. AlpR, SelekS, AlpSI,Taşkin A, Koçyiğit A. Oxidative and antioxidative balance in patients of migraine. Eur Rev Med Pharmacol Sci 2010; 14(10): 877-82.

38. Fernandez-Patron C, Stewart KG, Zhang Y, Koivunen E, Radomski MW, Davidge ST. Vascular matrix metalloproteinase-2-dependent cleavage of calcitonin gene-related peptide promotes vasoconstriction. Circ Res 2000; 87(8): 670-6.

39. Wang Q, Yan J, Chen X, Li J, Yang Y, Weng J, et al. Statins: multiple neuroprotective mechanisms in neurodegenerative diseases. Exp Neurol 2011; 230(1): 27-34.

40. Eroğlu F, Eroğlu HE. Ratlarda Analjezi ve Anestezi, Küçük Deney Hayvanlarından Rat. In: Yücel O. (ed.), JCAM, Matris Tanıtım Baskı Hizmetleri Hilal Mahallesi (Yıldız) 4. Cadde, 701. Sokak, No: 20/A 06550 Çankaya, Ankara, Türkiye, 2012; ISBN: 978-605-87501-2-8, 52-59.

41. Jagatic J, Weiskopf R. A fluorescent method for staining mast cells. Arch Pathol 1966; 82(5): 430-3.

42. Erel O. A novel automated method to measure total antioxidant response against potent free radical reactions. Clin Biochem 2004; 37(2): 112-9.

43. Erel O. A new automated colorimetric method for measuring total oxidant status. Clin Biochem 2005 38(12): 1103-11.

44. Özyiğit F. Nöropatik Farelerde Oluşan Mekanik Allodini Ve Hiperaljezi Üzerine Minosiklin'in Tek Başına Ve Morfin İle Birlikte Kullanıldığındaki Etkisi. T.C. Trakya Üniversitesi Tıp Fakültesi Farmakoloji Ana Bilim Dalı, Yüksek Lisans Tezi, 2007.

45. Akerman S, Holland PR, Goadsby PJ. Diencephalic and brainstem mechanisms in migraine. Nat Rev Neurosci 2011; 12(10): 570-84.

46. Greco R, Tassorelli C, Cappelletti D, Sandrini G, Nappi G. Activation of the transcription factor NF-kappaB in the nucleus trigeminalis caudalis in an animal model of migraine. Neurotoxicology 2005; 26(5): 795-800.

47. Pardutz A, Szatmári E, Vecsei L, Schoenen J. Nitroglycerin-induced nNOS increase in rat trigeminal nucleus caudalis is inhibited by systemic administration of lysine acetylsalicylate but not of sumatriptan. Cephalalgia 2004; 24(6): 439-45.

48. Suwattanasophon C, Phansuwan-Pujito P, Srikiatkhachorn A. 5-HT(1B/1D) serotonin receptor agonist attenuates nitroglycerinevoked nitric oxide synthase expression in trigeminal pathway. Cephalalgia 2003; 23(8): 825-32.

49. Pardutz A, Krizbai I, Multon S, Vecsei L, Schoenen J. Systemic nitroglycerin increases nNOS levels in rat trigeminal nucleus caudalis. Neuroreport 2000; 11(14): 3071-5.

50. Varga H, Pardutz A, Vamos E, Plangar I, Egyud E, Tajti J, et al. Cox2 inhibitor attenuates NO-induced nNOS in rat caudal trigeminal nucleus. Headache 2007; 47(9): 1319-25.

51. Pardutz A, Hoyk Z, Varga H, Vecsei L, Schoenen J. Oestrogenmodulated increase of calmodulin-dependent protein kinase II (CamKII) in rat spinal trigeminal nucleus after systemic 
nitroglycerin. Cephalalgia 2007; 27(1): 46-53.

52. Yin Z, Fang Y, Ren L, Wang X, Zhang A, Lin J, Li X. Atorvastatin attenuates NF-kappaB activation in trigeminal nucleus caudalis in a rat model of migraine. Neurosci Lett 2009; 465(1): 61-5.

53. Pradhan AA, Smith ML, McGuire B, Tarash I, Evans CJ, Charles A. Characterization of a novel model of chronic migraine. Pain 2014; 155(2): 269-74.

54. Iversen HK, Olesen J, Tfelt-hansen P. Intravenous nitroglycerin as an experimental-model of vascular headache basic characteristics. Pain 1989; 38(1): 17-24.

55. Olesen J, Thomsen LL, Iversen H. Nitric oxide is a key molecule in migraine and other vascular headaches. Trends Pharmacol Sci 1994; 15(5): 149-53.

56. Capuano A, De Corato A, Lisi L, Tringali G, Navarra P, Dello Russo C. Proinflammatory-activated trigeminal satellite cells promote neuronal sensitization: relevance for migraine pathology. Mol Pain 2009; 5: 43.

57. Villalón CM, Olesen J. The role of CGRP in the pathophysiology of migraine and efficacy of CGRP receptor antagonists as acute antimigraine drugs. Pharmacol Ther 2009; 124(3): 309-23.

58. Kuzawińska O, Lis K, Cudna A, Bałkowiec-Iskra E. Gender differences in the neurochemical response of trigeminal ganglion neurons to peripheral inflammation in mice. Acta Neurobiol Exp (Wars) 2014; 74(2): 227-32.

59. Ward TN. Migraine diagnosis and pathophysiology. Continuum (Minneap Minn) 2012; 18(4): 753-63.

60. Sarrouilhe D, Dejean C, Mesnil M. Involvement of gap junction channels in the pathophysiology of migraine with aura. Front Physiol 2014; 5: 78.

61. Ji Y, Murphy AZ, Traub RJ. Estrogen modulates the visceromotor reflex and responses of spinal dorsal horn neurons to colorectal stimulation in the rat. J Neurosci 2003; 23(9): 3908-15.

62. Sachs M, Pape HC, Speckmann EJ, Gorji A. The effect of estrogen and progesterone on spreading depression in rat neocortical tissues. Neurobiol Dis 2007; 25(1): 27-34.

63. Peroni RN, Orliac ML, Abramoff T, Ribeiro ML, Franchi AM, AdlerGraschinsky E. Participation of CGRP and prostanoids in the sexlinked differences of vascular anandamide effects in mesenteric beds of Sprague-Dawley rats. Eur J Pharmacol 2007; 557(1): 49-57.

64. Wrobel Goldberg S, Silberstein SD. Targeting CGRP: A New Era for Migraine Treatment. CNS Drugs 2015; 29(6): 443-52.

65. Messlinger K, Lennerz JK, Eberhardt M, Fischer MJ. CGRP and $\mathrm{NO}$ in the trigeminal system: mechanisms and role in headache generation. Headache 2012; 52(9): 1411-27.

66. Mitsikostas DD, Sanchez del Rio M. Receptor systems mediating cfos expression within trigeminal nucleus caudalis in animal models of migraine. Brain Res Brain Res Rev 2001; 35(1): 20-35.

67. Greco R, Tassorelli C, Cappelletti D, Sandrini G, Nappi G. Activation of the transcription factor NF-kappaB in the nucleus trigeminalis caudalis in an animal model of migraine. Neurotoxicology 2005; 26(5): 795-800.

68. Zhang X, Kainz V, Zhao J, Strassman AM, Levy D. Vascular extracellular signal-regulated kinase mediates migraine-related sensitization of meningeal nociceptors. Ann Neurol 2013; 73(6): 741-50.

69. Chenn A, Walsh CA. Increased neuronal production, enlarged forebrains and cytoarchitectural distortions in beta-catenin overexpressing transgenic mice. Cereb Cortex 2003; 13(6): 599-606.
70. Yang J, Zhang X, Wu Y, Zhao B, Liu X, Pan Y, et al. Wnt/B-catenin signaling mediates the seizure-facilitating effect of postischemic reactive astrocytes after pentylenetetrazole-kindling. Glia 2016; 64(6):1083-91.

71. Siva A, Murat H. editors, Baş Ağrısı Epidemiyolojisi, i.Ü. Cerrahpaşa Tıp Fakültesi Sürekli Tıp Eğitimi Etkinlikleri. Baş, Boyun, Bel Ağrıları. Siva A 2002; 30, 9-14.

72. Sarrouilhe D, Dejean C, Mesnil M. Involvement of gap junction channels in the pathophysiology of migraine with aura. Front Physiol 2014; 5: 78.

73. Banach M, Piskorska B, Czuczwar SJ, Borowicz KK. Nitric oxide, epileptic seizures, and action of antiepileptic drugs. CNS Neurol Disord Drug Targets 2011; 10(7): 808-19.

74. Reiss $A B$, Wirkowski E. Statins in neurological disorders: mechanisms and therapeutic value. ScientificWorldJournal 2009; 9: 1242-59.

75. Kampoli AM, Tousoulis D, Tentolouris C, Stefanadis C. Novel agents targeting nitric oxide. Curr Vasc Pharmacol 2012; 10(1): 61-76.

76. Banach M, Czuczwar SJ, Borowicz KK. Statins - are they anticonvulsant? Pharmacol Rep 2014; 66(4): 521-8.

77. Schmidt HH, Walter U. NO at work. Cell 1994; 78(6): 919-25.

78. Rikitake Y, Liao JK. Rho GTPases, statins, and nitric oxide. Circ Res 2005; 97(12): 1232-5.

79. Sarrouilhe D, Dejean C, Mesnil M. Involvement of gap junction channels in the pathophysiology of migraine with aura. Front Physiol 2014; 5: 78.

80. Yin Z, Fang Y, Ren L, Wang X, Zhang A, Lin J, et al. Atorvastatin attenuates NF-kappaB activation in trigeminal nucleus caudalis in a rat model of migraine. Neurosci Lett 2009; 465(1): 61-5.

81. Brandes JL. The influence on migraine: A systematic review. JAMA 2006; 295(15): 1824-30.

82. Bereiter DA, Cioffi JL, Bereiter DF. Oestrogen receptorimmunoreactive neurons in the trigeminal sensory system of male and cycling female rats. Arch Oral Biol 2005; 50(11): 971-9.

83. Marcus DA. Estrogen and tension-type headache. Curr Pain Headache Rep 2001; 5(5): 449-53.

84. Shimomura T, Murakami F, Kotani K, Ikawa S, Kono S. Platelet nitric oxide metabolites in migraine. Cephalalgia 1999; 19(4): 218-22.

85. D'Amico D, Ferraris A, Leone M, Catania A, Carlin A, Grazzi I, et al. Increased plasma nitrites in migraine and cluster headache patients in interictal period: basal hyperactivity of L-arginine NO patway? Cephalalgia 2002; 22(1): 33-6.

86. Stirparo G, Zicari A, Favilla M, Lipari M, Martelletti M. Linked activation of nitric oxide synthase and cyclooxygenase in peripheral monocytes of asymptomatic mi graine without aura patients. Cephalalgia 2000; 20(2): 100-6.

87. Gruber HJ, Bernecker C, Lechner A, Weiss S, Wallner-Blazek M, Meinitzer $A$, et al. Increased nitric oxide stress is associated with migraine. Cephalalgia 2010; 30(4): 486-92.

88. Lucchesi C, Baldacci F, Cafalli M, Chico L, Lo Gerfo A, Bonuccelli U, et al. Evidences of reduced antioxidant activity in patients with chronic migraine and medication-overuse headache. Headache 2015; 55(7): 984-91.

89. Berk M, Dean O, Drexhage H, McNeil JJ, Moylan S, O'Neil A, et al. Aspirin: A review of its neurobiological properties and therapeutic potential for mental illness. BMC Med 2013; 11: 74.

90. Edvinsson L, Warfvinge K. Recognizing the role of CGRP and CGRP 